\title{
0 Impacto das Resinas na Economia: Principais Indicadores Econômicos
}

\author{
Suzana Borschiver, Adelaide Antunes \\ Escola de Química, UFRJ
}

\section{Pedro Wongtschowski \\ Oxiteno, RJ}

Resumo: Este artigo tem como objetivo principal proporcionar o conhecimento para a compreensão do impacto da indústria química na economia brasileira. Para tanto, utiliza-se como uma das ferramentas essenciais o Sistema de Contas Nacionais (SCN) do IBGE (Instituto Brasileiro de Geografia e Estatística), órgão federal produtor de estatísticas oficiais. Este sistema, através das suas Tabelas de Recursos e Usos, possibilita a geração de informações importantes para tomadas de decisões de empresas, governo e universidades/centros de pesquisa, através de uma visão econômica de produtos e atividades que fazem parte do sistema produtivo do país. No caso deste artigo, utiliza-se como exemplo o grupo das resinas, procurando-se demonstrar, seja pela ótica da oferta ou da demanda, o impacto destas na economia brasileira, através de alguns indicadores econômicos tais como: produção, consumo intermediário e importação.

Palavras-chave: Resinas, indústria química, sistema de contas nacionais, IBGE, produção, consumo intermediário, importação.

\section{The Impact of Resins on the Economy: Key Economic Indicators}

Abstract: This article is aimed at analysing the impact of chemical industries on the Brazilian economy. One of essential tools for doing that in the Sistema de Contas Nacionais (System of National Accounts) - SCN of the Instituto Brasileiro de Geografia e Estatística - IBGE, the official federal statistics agency. The Input and OutPut Tables in this system make it possible to generate information that can support the decision-making processes of companies, governments and universities/research centers, through providing an economic view of products and activities that comprise the country's production system. In this article, RESINS are the subject of analysis. Their impact on the Brazilian economy will be demonstrated, both from a supply and demand viewpoint, using a number of economic indicators, such as production, intermediate consumption and imports.

Keywords: Resins, chemical industries system, IBGE, production, intermediate consumption, imports.

\section{Introdução}

A apresentação dos dados sobre a economia de um país, relativos a produção, renda, emprego, investimento, consumo e outros fatores econômicos, envolve a utilização de uma gama de informações que, para serem compreensíveis, consistentes e comparáveis entre si, devem ser organizadas de acordo com conceitos, definições e metodologias definidas pelas Contas Nacio- nais (Rosseti, 1982). O Sistema de Contas Nacionais (SCN) adotado pela maioria dos países relaciona uma ou mais características dos bens e serviços produzidos com os usos a que se destinam, com os insumos utilizados, com a tecnologia empregada e/ou a organização da produção. Este relacionamento permite caracterizar cada atividade da economia assim como comparar informações destas atividades investigadas nos censos e nas demais pesquisas industriais. O desenvolvimento

Autor para correspondência: Suzana Borschiver, Escola de Química, UFRJ, Rua Haia, 87 - Moneró; Ilha do Governador, CEP: 21920-180, Rio de Janeiro, RJ.E-mail: suzana@eq.ufrj.br 
metodológico do SCN é validado por inúmeras instituições internacionais dedicadas à compilação de estatísticas oficiais, como por exemplo a Eurostat da Comunidade Européia, a Organização para a Cooperação Econômica e a ONU (Organização das Nações Unidas). A referência mais importante para a construção de um sistema de Contabilidade Nacional é o Manual das Nações Unidas. No Brasil, o Sistema de Contas Nacionais é produzido pelo IBGE sendo composto por Tabelas de Recursos e Usos, pela Matriz de Insumo Produto, pelas Contas Econômicas Integradas ${ }^{1}$ e pelos Quadros Auxiliares de Emprego, Produtividade e Rendimento (Feijó, Carmem 2000, et alli).

As Tabelas de Recursos e Usos ${ }^{2}$ (TRU), ferramentas adotadas para este trabalho, apresentam os valores dos agregados macro-econômicos dos Produtos, Renda e Despesa por setores de atividade econômica. Essas tabelas são classificadas em Tabelas de Recursos de Bens e Serviços, e apresentam a oferta total de Bens e Serviços da Economia (produção e importação); em Tabelas de Usos de Bens e Serviços, ue apresentam o Consumo Intermediário (Consumo Industrial) e a Demanda Final (Exportação, Consumo Final e Formação Bruta de Capital), totalizando a demanda da economia.

Nestas tabelas (TRU) ${ }^{3}$, a economia está representada por 43 atividades, codificadas por dois dígitos e por 80 grupos de produtos, codificados por quatro dígitos.

\section{Metodologia}

Este trabalho apresenta indicadores econômicos para o grupo das RESINAS, identificado pelo código 1805 , de acordo com o IBGE. Este grupo compreende a fabricação de resinas propriamente ditas, fibras artificiais e sintéticas e elastômeros. Estes 3 setores são divididos, de acordo com o Cadastro de Atividades e Produtos do SCN, por 3 grandes subgrupos, descritos a seguir:

\section{1) Fabricação de resinas propriamente ditas:}

- Fabricação de Matérias Plásticas sob a forma de resinas, emulsões, dispersões, soluções, grãos, pós, escamas e semelhantes (formaldeído, uréiaformaldeído, melamina-formaldeído, epóxi, polietileno, poliestireno, copoli(cloreto de vinila/ acetato de vinila), PVA- poli(acetado de vinila), PVC- poli(cloreto de vinila), Acrílicas e Metacrílicas, ABS-Acrilonitrila Butadieno Estireno, Álcool Polivinílico, Poliésteres, Náilon-Poliamidas, Polipropileno, Acetato de celulose, Carboximetilcelulose, Tetrafluoretileno, Poliuretano, Película Celofane, Celulóide, incluindo também a polimerização de matérias plásticas para extrusão de fios sintéticos Polimerização de Superpoliamidas - Náilon, Poliéster; Polipropileno para fita ráfia e fios têxteis de outros materiais poliméricos para extrusão de fios e fibras têxteis) e fabricação de plastificantes

\section{2) Fabricação de fios e fibras artificiais e sin- téticas}

- Fabricação de fios, cabos e filamentos contínuos artificiais e sintéticos para fins têxteis ou industriais e fabricação de fibras cortadas artificiais e sintéticas (artificiais: raiom, viscose; sintéticas: poliéster, náilon, polipropileno, poliacrilico).

\section{3) Fabricação de Elastômeros}

- Fabricação de elastômeros e látices sintéticos (polibutadieno, polibutadienoestireno, NBRnitrílica ou copoli(butadieno/acrilonitrila), poliisopreno isobutileno; látex de polibutadieno, látex de polibutadienoestireno carboxilado, látex nitrílico e demais borrachas sólidas e látices sintéticos)

Para o estudo do comportamento econômico das RESINAS (1805), foi elaborado o fluxo da oferta e da demanda apresentado na figura 1, tomando-se como exemplo o ano de $1999^{4}$. Este fluxo permite analisar o

\footnotetext{
${ }^{1}$ As Contas Econômicas Integradas (CEIS) são construídas em torno de uma seqüência de contas de fluxos que descrevem de maneira agregada como se comporta a economia do país em um determinado período de tempo. Nessas contas são registrados, entre outros, os valores do PIB (Produto Interno Bruto), da Poupança e do Patrimônio do país (engloba ativos tangíveis, intangíveis e financeiros).

2 Vale ressaltar que para gerar as Tabelas de Recursos e Usos - TRU foram concebidos procedimentos de cálculo que mesclam projeções referentes à série de 1990 em diante, baseadas em índices de volume e preço, e informações obtidas diretamente, acompanhadas por análises de coerência econômica e contábil de suas operações.

${ }^{3}$ As atividades e os grupos de produtos estão no Sistema de Contas Nacionais: Brasil / IBGE.

${ }^{4}$ Cabe ressaltar que o comportamento em relação aos percentuais manteve-se constante durante toda a década
} 
grupo de produtos Resinas, sob as óticas da oferta e demanda, destacando-se as principais atividades econômicas produtora e consumidoras de resinas.

A seguir são conceituadas ${ }^{5}$ as identidades contábeis presentes na Figura 1 levando-se em consideração que por definição a Oferta Total a preço de consumidor = Demanda Total a preço de consumidor.

Atividade Econômica - Conjunto de unidades de produção ou consumo (indústria) caracterizada pelo produto produzido ou consumido, classificado conforme sua produção principal/consumo. No caso das resinas, a atividade Refino de Petróleo e Indústria Petroquímica, código 18, representa a principal atividade produtora e as atividades Artigos de Plástico (21), Indústria Têxtil (22); Indústria da Borracha (16), Químicos Diversos (19) e Refino de Petróleo e Indústria Petroquímica (18), representam as principais atividades consumidoras.

Consumo Intermediário- Valor dos bens ou serviços utilizados como insumos de processo da produção industrial.

\section{Comportamento das RESINAS (1805) na Economia - 1999}

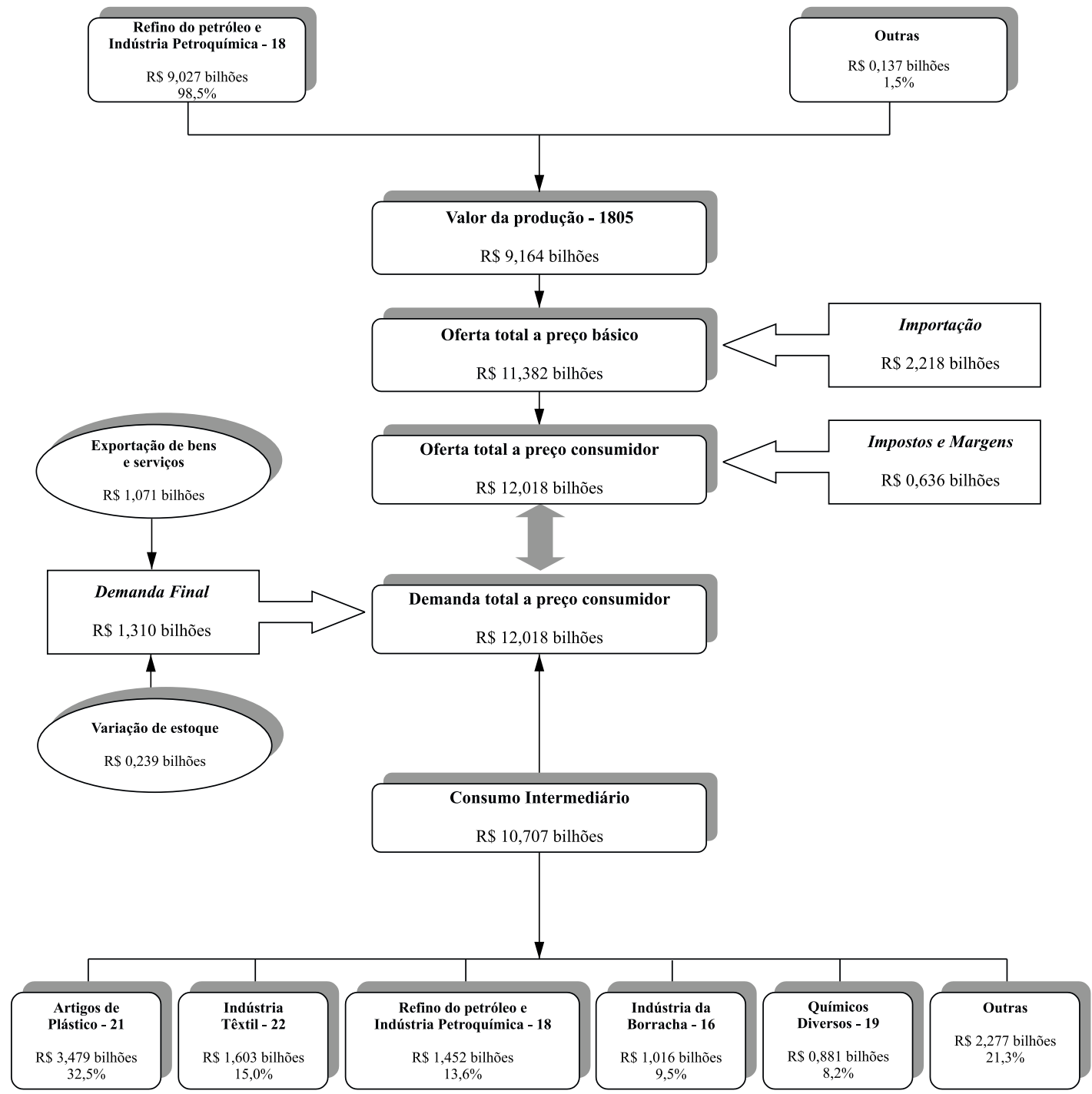

Figura 1. Quadro esquemático da metodologia de análise por produto sob a ótica da oferta e da demanda. Dados da Tabela de Recursos e Usos / IBGE, 1990 - 1999

\footnotetext{
5 O objetivo deste glossário é dar uma idéia geral sobre os conceitos dos agregados macroeconômicos presentes ao longo do trabalho. Para maior rigor nos conceitos ver Sistema de Contas Nacionais - Tabelas de Recursos e Usos - Metodologia, 1997.
} 
Valor da Produção - Valor dos bens e serviços produzidos e comercializados. (no caso das resinas, corresponde a atividade 18).

Exportação de bens e serviços - Valor dos bens e serviços exportados avaliados a preços FOB (Free on Board), ou seja, incluindo somente o custo de comercialização interna até o porto de saída das mercadorias. (no caso das resinas, correspondeu a $\mathrm{R} \$ 1,07$ bilhões no ano de 1999).

Importação de bens e serviços - Valor dos bens $\mathrm{e}$ serviços adquiridos pelo Brasil do resto do mundo, valorados a preço CIF (Cost, Insurance and Freight), ou seja, incluindo no preço das mercadorias os custos com o seguro e frete. (no caso das resinas, correspondeu a $\mathrm{R} \$ 2$ bilhões no ano de 1999).

Impostos sobre a produção, importação e produtos- Impostos e taxas pagos pelas unidades de produção e que incidem sobre a produção, comercialização, importação e a exportação de bens e serviços, como o ICMS (Imposto sobre Circulação de Mercadoria e Serviços), o IPI (Impostos sobre Produtos Industrializados) e o II (Imposto de Importação).

Variação de estoques - Diferença entre os valores dos estoques de mercadorias finais, de produtos semimanufaturados, bens em processo de fabricação e matérias-primas dos setores produtivos no início e no fim de um ano, avaliados aos preços médios correntes do período.

Oferta Total a preço básico = Valor da Produção + Valor da Importação. (no caso das resinas, correspondeu a R \$11,382 bilhões no ano de 1999).

Oferta Total a preço de consumidor = Oferta Total a preço básico do produto + Margens + Impostos. (no caso das resinas, correspondeu a R $\$ 12,018$ bilhões no ano de 1999).

Demanda Final = Exportação de bens e serviços + Variação de Estoque. (no caso das resinas, correspondeu a R \$1,3 bilhões no ano de 1999).

Demanda Total a preço de consumidor $=$ Consumo Intermediário + Demanda Final.(no caso das resinas, correspondeu a $\mathrm{R} \$ 12,018$ bilhões no ano de 1999).

Análise do Comportamento das resinas (1805) na Economia Brasileira

A Economia pode ser dividida de diversas maneiras conforme o objetivo de estudo e pesquisa. Para o IBGE, o sistema econômico é dividido em 3 grandes classes: Agropecuária, Indústria e Serviços.

Em 1999, o valor de produção total da economia foi na ordem de $\mathrm{R} \$ 1,6$ trilhões.

Levando-se em consideração que o IBGE conceitua o termo Indústria como um somatório das Indústrias de Transformação, das Indústrias Extrativas, dos Serviços Industriais de Utilidade Pública e da Construção Civil, só o percentual de produção da Indústria de Transformação representou em 1999, 39,5\% de todo o valor da produção do país. Deste total, $14 \%$ corresponderam a produtos químicos, sendo que todo o valor do grupo de resinas (1805) equivaleram a $11 \%$ destes, conforme o esquema da Figura 2.

Em valores monetários, a produção total de produtos químicos totalizou $\mathrm{R} \$ 89$ bilhões em 1999. Isso significa que 5,6\% do total de insumos produzidos pela economia são produtos químicos. Verifica-se ainda que $\mathrm{R} \$ 9$ bilhões corresponderam a produção de resinas.

Conforme Figura 1, nota-se que a principal atividade produtora de resinas é a Refino de Petróleo e Indústria Petroquímica ${ }^{6}$.

Pelo lado do consumo, a indústria de transformação representa $52,1 \%$ de tudo que é consumido no país. Deste total, 19,0\% correspondem a produtos químicos, sendo que o grupo das resinas correspondem a 13,3\% destes, conforme o esquema da Figura 3.

Em valores monetários, o consumo industrial de produtos químicos foi de $\mathrm{R} \$ 91$ bilhões, representando $11 \%$ em 1999 de todos os bens e serviços utilizados como insumos no processo de produção no país. $\mathrm{O}$ valor do grupo de resinas consumido na economia foi de R\$ 10,7 bilhões, vide Figura 1.

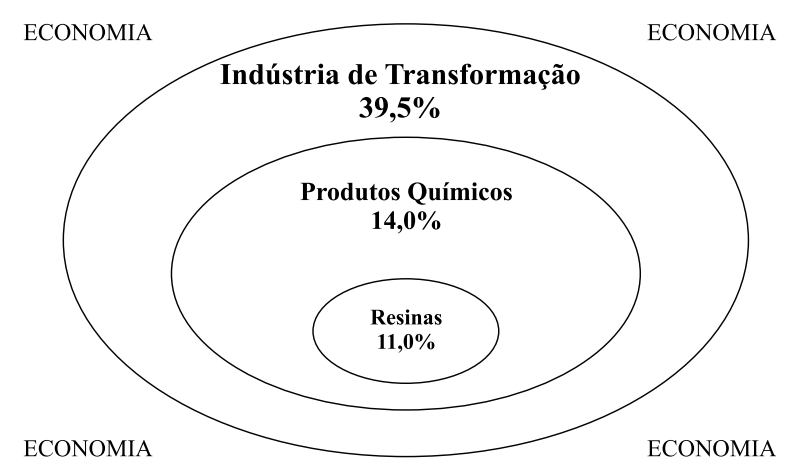

Figura 2. Participação das Resinas no Valor de Produção da Economia. Dados da Tabela de Recursos e Usos / IBGE, 1990 - 1999.

\footnotetext{
${ }^{6}$ Nota-se o alto grau de agregação desta atividade, que junta dois setores interligados mas distintos
} 


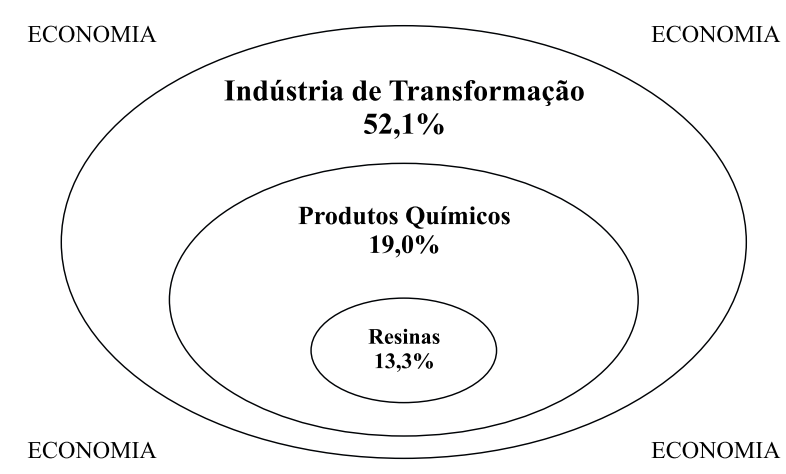

Figura 3. Participação das Resinas no Consumo Intermediário da Economia. Dados da Tabela de Recursos e Usos / IBGE, 1990 - 1999.

Os dados do ranking das principais atividades consumidoras de resinas não surpreendem, destacando-se as atividades Artigos de Plástico, Indústria Têxtil, Refino de Petróleo e Indústria Petroquímica, Indústria da Borracha, Químicos Diversos e Outras (Figura 1).

Vale ressaltar que a atividade Químicos Diversos, de acordo com o IBGE, engloba a fabricação de adesivos, gomas adesivas e colas ${ }^{7}$ e que foram inseridas em "Outras" as atividades com participação igual ou menor que $5 \%$ no consumo intermediário de resinas.

Esta relação percentual de produção e consumo manteve-se praticamente constante ao longo da década de 90.

Em relação ao comportamento das importações (Gráfico 1), o Coeficiente de Penetração das Importações $\left(\mathrm{M} /(\mathrm{M}+\mathrm{VP})^{8}\right.$, apresentou um aumento de apro-

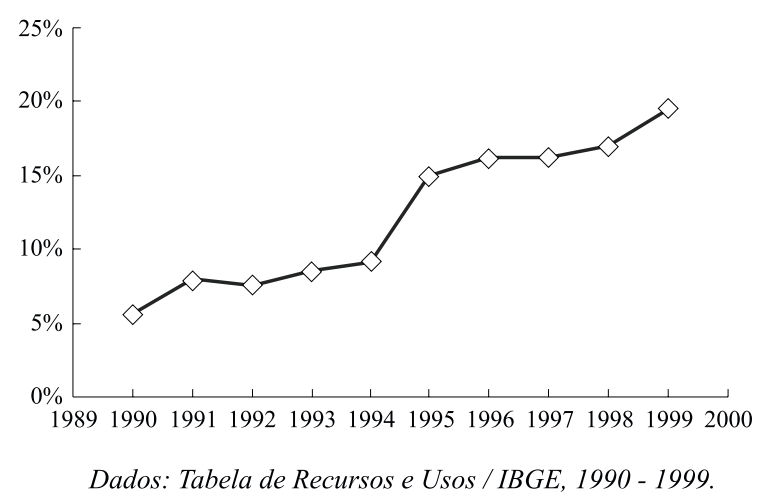

Gráfico 1. Coeficiente de Penetração RESINAS (1805) - 1990/1999

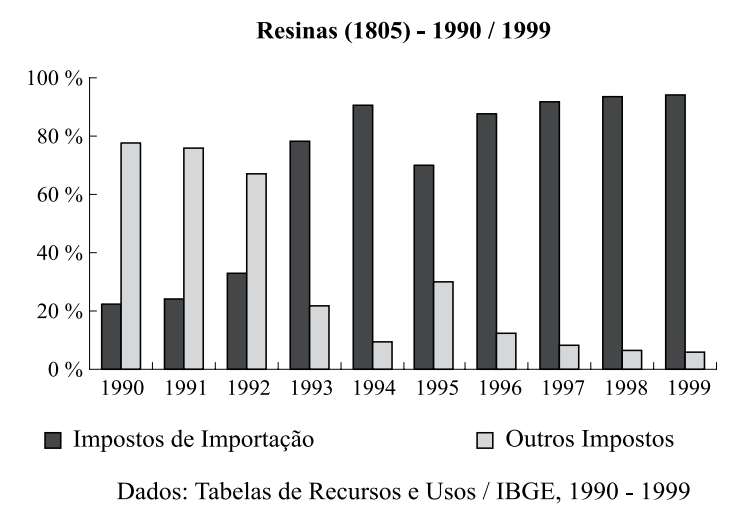

Gráfico 2. Série Temporal dos Impostos sobre RESINAS (1805) - 1990/ 1999

ximadamente $254 \%$ de 1990 (5,5\%) em relação a 1999 (19,5\%), sendo o dobro do valor das exportações.

Em relação aos impostos e margens (comércio e transporte $)^{9}$, nota-se que estes pesaram aproximadamente 5,3\% em relação a Oferta (Total a preço de consumidor) durante a década de 90 , sendo que do total de Impostos atribuídos às resinas, o Imposto de Importação foi o que mais cresceu entre 1990 e 1999, passando respectivamente de 22\% a 94\% (Gráfico 2).

\section{Conclusão}

É incontestável a importância da análise da informação nas sociedades modernas, constituindo-se, fundamentalmente em elemento para tomada de decisões. Neste contexto, as Tabelas de Recursos e Usos do Sistema de Contas Nacionais atuam como ferramentas necessárias para expressar os fatos econômicos e sociais. Para constituírem-se em informações consistentes os dados devem ser ordenados, sistematizados e incluídos em sistemas de classificação, de modo a retratar adequadamente os diversos fenômenos de um mundo cada vez mais complexo, onde é exigida antes de tudo uma abordagem multidisciplinar.

A análise setorial da economia constitui-se em um dos principais desafios para estudiosos e analistas econômicos. O que, a princípio, parece um trivial

\footnotetext{
${ }^{7}$ Outros produtos fazem parte desta atividade, tais como adubos, fertilizantes, pigmentos, corantes, defensivos agrícolas, produtos de limpeza e explosivos.

8 Índice bastante utilizado por especialistas da área de análise setorial, onde M é o valor das Importações e VP o valor da Produção.

${ }^{9}$ As margens de comércio e transporte são elementos que incidem sobre o produto, aumentando o valor dos bens, nacionais ou importados, na passagem do preço básico ou CIF para o preço de consumidor.
} 
exercício de taxionomia mostra-se extremamente complexo quando se observa cuidadosamente a atual estrutura de produção, consumo, importação e exportação.

Através dessa análise, ficou constatado a importância das Resinas que impactam a jusante e a montante em atividades importantes da economia

Observa-se que a atividade que engloba "Refino de Petróleo e a Indústria Petroquímica" representa um exemplo do alto grau de agregação das atividades do Sistema de Contas Nacionais. Embora o IBGE a considere como uma única atividade econômica,de acordo com a lógica de processamento químico, esta deveria ser desagregada em pelo menos duas atividades formadas respectivamente pelo Refino de Petróleo e pela Indústria Petroquímica, dois elos da cadeia produtiva das Resinas.

$O$ fato de haver também consumo industrial de Resinas por esta mesma atividade é justificado pela passagem pelas unidades de pré-forma/bobinas das resinas do primeiro transformador para o segundo transformador, unidades estas consideradas como estabelecimentos industriais distintos pelo IBGE.

Em síntese, a metodologia desenvolvida permite verificar, entre outras conclusões, os valores reais da química na economia (dados estes normalmente fornecidos das associações e sindicatos), o seu relacionamento e impacto com outras atividades, além de proporcionar também importantes informações, de alto grau de relevância, que sistematizadas, constituem em uma ferramenta poderosa para tomadas de decisões de empresas e governo.

\section{Referências Bibliográficas}

1. Feijjó, Carmem Aparecida; Ramos, Roberto Luis Olinto [et alli] - "Contabilidade Social - O Novo Sistema de Contas Nacionais do Brasil", Rio de Janeiro: Editora Campus, (2000). ISBN 85-352-0685-X.

2. Rosseti, José Paschoal. "Contabilidade Nacional - Uma Abordagem Introdutória “ Editora Atlas, $3^{\mathrm{a}}$ edição, São Paulo, (1982).

3. "Sistema de Contas Nacionais - Tabelas deRecursos e Usos - Metodologia", Departamento de Contas Nacionais. Rio de Janeiro: IBGE. Série Texto para Discussão, n.88 (1997).

Recebido: 09/10/01

Aprovado: 14/01/02 